\title{
Review of Herbert Gintis's Individuality and Entanglement: The Moral and Material Bases of Social Life. Princeton: Princeton University Press, 2017, 357 pp.
}

\author{
MiCHIRU NAGATSU \\ University of Helsinki
}

In his own words, Herbert Gintis's latest book is "an analysis of human nature and a tribute to its wonders" (3). ${ }^{1}$ More prosaically, it is a collection of essays, some of which are original and others published elsewhere. Instead of being structured around topics in decision and game theory, like his previous book (2009), this book develops interrelated themes, such as the evolutionary origins of moral sense, its central role in political games, and the socially entangled nature of human rationality and individuality. Some chapters develop Gintis's vision of the unified behavioral sciences by model-building demonstrations; others do so by reflecting on history and methodology.

The demonstrative part of the book models the evolution of human socio-political systems, power relations in markets, altruism, voter turnout, and Walrasian dynamics-drawing on decision theory, game theory, evolutionary theory, and complexity theory. This part offers readers familiar with formal apparatus an excellent overview of the Gintis's recent contributions to the field. The reflective part discusses the nature of rational actor models, provides an intellectual history of sociology and economics, and advocates the unification of the behavioral sciences. This part gives readers interested in history and philosophy of the behavioral sciences an insightful first-hand account by one of the leading figures in the field.

In this review, I focus on Gintis's advocacy of interdisciplinarity, mostly commenting on the reflective part of the book. I also include a meta-review-a review of three reviews of the book, written by other scientists. Regarding the demonstrative part, I strongly recommend the readers to carefully study it themselves, because that is the only way to really appreciate the original insights of the formal work. (And if they are too busy to read all of it, they should at least read Chapters 3 and 9.)

${ }^{1}$ All references are to the book reviewed unless indicated otherwise. 
Herbert Gintis is an outstanding veteran figure, who freely travels across boundaries between economics, sociology, anthropology, political science, psychology, and biology. He calls his field "the behavioral sciences", defining them as "the social sciences plus sociobiology (the biological study of the social behavior of living organisms)" (267). I will follow this definition throughout this review. His take on interdisciplinarity is well-summarized in the last chapter (Chapter 12: The Future of the Behavioral Sciences), where he observes:

I have found that when I attack problems concerning human behavior, restricting myself to knowledge from a single academic discipline leaves me partially blind. I find I do much better by combining insights and models from a variety of behavioral disciplines, letting my research wander about in whatever direction seems fruitful at the moment (67, my italics).

Gintis sometimes characterizes his approach as transdisciplinary, but, in my view, it is more appropriately captured by what Steve Fuller (2013) calls a 'deviant interdisciplinary' perspective. A deviant interdisciplinarian tries to reverse "epistemically undesirable tendencies inherent in disciplinized inquiry" (Fuller 2013, 1900). In contrast, what Fuller calls a 'normal interdisciplinaran' proceeds by taking this division for granted and assembling disciplines post hoc, respecting each participating discipline's expertise. Gintis is clearly not a normal interdisciplinarian-which is a Kuhnian notion-since he denies the maturity of most of the behavioral sciences in the first place. For example, Gintis's insistence that all behavioral scientists should adopt a common core-decision theory and game theory as analytic modelling frameworks-suggests the deviant nature of his approach. This deviant nature will be resisted by many social scientists who do not have expertise in, or appreciation of, formal modelling methods.

The argument Gintis gives for his deviant interdisciplinarity, which is an updated version of the argument in his previous book (2009, Chapter 12) is as follows: the behavioral science disciplines co-exist while holding mutually incompatible models of human nature (or human society, or human behavior). However, since there is only one truth, at most one of these views is correct. ${ }^{2}$ Living with this status quo of mutual incompatibility hinders scientific progress. To make progress,

\footnotetext{
${ }^{2}$ Gintis thinks that, in fact, these views are all false, strictly speaking. The book aims to integrate them by making them correct and mutually consistent with each other.
} 
we must establish a common core analytic framework that serves as (1) a clearinghouse of compatibility between the behavioral sciences, as it were, and (2) a set of shared theoretical templates in which progress can be made in a cumulative fashion.

This argument is based on the assumption that a discipline (which Gintis defines as a common set of questions and communication platforms) is an effective unit of epistemic inquiry to the extent that it roughly coincides with some analytical foundations, such as mathematically formulated evolutionary theory. Since many behavioral sciences lack one, his argument goes, the current disciplinary divisions (in particular, those organized by the departmental system used by many universities) are not epistemically optimal. So, ultimately, Gintis subscribes to the Kuhnian notion of normal science, claiming only that the behavioral sciences have not reached the maturity of a normal science, with the exception of economics. He sounds deviant, but actually is very traditional in this sense.

I have two worries here, one concerning Gintis's optimism about scientists' cognitive capacities, and the other concerning his neglect of underdetermination. My first worry is, more specifically, about his claim that in order to achieve his vision of the unified or integrated behavioral sciences, it is necessary for "the researcher to be fluent in both analytical model building and the thick description of social behavior" (271). Although ideal, there are probably some cognitive constraints on how 'fluent' one researcher can be in both during her career. Interdisciplinary collaboration after disciplinary training is an obvious alternative to the one-person interdisciplinarity, although it poses its own cognitive and institutional challenges. Gintis has collaborated with many researchers and seems optimistic about the prospect of collaboration: "Cross-disciplinary collaboration works well" (267).

My second worry is that Gintis significantly downplays the problem of underdetermination of theory by observation. He notes: "While it is not uncommon for scientists to disagree, there is only one truth in science and standard scientific protocols dictate that disagreements be adjudicated until some resolution is achieved" (268). This is probably the right attitude for a working scientist, but there is often, if not always, room for scientists' epistemic as well as non-epistemic interests to direct them to different, incommensurable or incompatible conclusions (for a case study of incommensurable game theoretic models of social norms, see Paternotte and Grose 2013). This is not 
about marginal cases in which ideologies create a bogus science-rather, underdetermination is a fundamental aspect of many successful scientific disciplines (Longino 2013; Chang 2012; Mitchell and Dietrich 2006).

Readers of this review might wonder how other behavioral scientists respond to Gintis's deviant interdisciplinarity. In order to get a sense of the responses, I have identified three published reviews of this book in an economics, a psychology and a biology journal. Below, I give a metareview - a review of book reviews of the book I am reviewing, while at the same time reviewing the book itself.

First, and perhaps most interesting for the readership of this journal, Eyal Winter (2017), who is a professor of economics at the Hebrew University of Jerusalem, gives a big cheer for Gintis's intellectual imperialism:

I, like Gintis, believe that interdisciplinary research is crucial for real advancements in our understanding of social phenomena. I also believe that it is economics that has to perform most of the courtship in this relationship. Economics is often hailed or blamed for its academic imperialism. [...] For us economists to take the lead on paving the way for interdisciplinary work in the social sciences would be the right thing to do both morally and practically. Morally, because we are the invaders; practically, because economics is primarily about incentives and we need new research incentive schemes within and across disciplines to break disciplinary chauvinism and motivate interdisciplinary research (140).

This comment significantly inflates Gintis's point that other social sciences "are in such serious need of a unifying theoretical framework that a little imperialism from more successful fields should be welcome" (xviii). In turning this little imperialism into a moral duty of the invaders, Winter underestimates how much revision Gintis demands of the standard economic methodology, such as giving up methodological individualism (Chapters 3 and 5); letting go of the selfishness assumption (Chapters 2 and 6); and complementing equilibrium models with dynamic ones in the study of markets while integrating methods and insights from other disciplines along the way (Chapter 11). Some of these changes are surely easier than others, but collectively they may be 
as demanding as requiring non-economists to adopt decision theory and game theory as their core analytic frameworks.

In stark contrast, Dwight Read (2017), a professor of anthropology at the University of California, Los Angeles, bluntly dismisses the achievements of the book. In addition to the complaint that Gintis does not cite his book, Read makes two criticisms. First, he criticizes the ubiquity of "[t]he attribution of wide-ranging explanatory power to what are simply small pieces of a much larger picture, such as gene-culture co-evolution" (4). This is a somewhat surprising comment given Read's own work, which tries to explain how the increase in short-term memory of our ancestors relates to the evolution of human societies. This seems to me exactly an example of gene-culture co-evolution, which is discussed extensively in Gintis's book (in particular, in Chapters 1, 2, 8 and 10). I suspect what Read really means by "small pieces of a much larger picture" are analytic models, which need to be supplemented by other concepts and field data. But if this is the case, there is no methodological disagreement, because Gintis explicitly notes the importance of "conceptual sophistication in dealing with ethnographic and historical data, as well as a deep feeling for the less formally modeled aspects of social life" (271).

Read's second criticism is that Gintis fails to make a basic anthropological distinction between emic and etic concepts. Emic concepts are those concepts used by the native populations under study to understand their own world (such as gods' will); etic concepts are used by scientists to explain the natives' belief systems and practices (such as the need for social cohesion). Read argues that Gintis's rational model of voter turnout (Chapter 3: Distributed Effectivity: Political Theory and Rational Choice) fails because its etic assumption about voters' beliefs and preferences may be different from its emic counterparts. I think that this criticism is misguided, because Gintis does crucially rely on the data about people's reported beliefs and behavior in refuting his rival theories of voter turnout (see Section 3.6). How rational choice models are related to the actors' self-understanding of their own behavior is an important theme in the philosophy of social science, which is also discussed in economics as a use of 'as if' models. Although I cannot discuss this theme in more detail here, I should note that Read's methodological requirement that the etic concepts should coincide with emic ones seems to be too restrictive, especially when 
one's goal is to explain behavioral patterns, rather than understand how the actors see the world.

Gintis also touches upon the conflation of the emic and the epic (see Sections 3.2 and 6.5). His rational actor model captures the trade-off between three distinct motivations: material (self-regarding), prosocial (other-regarding), and moral (universal). In defending this model, Gintis clearly cautions against assuming that the rational actor model is incompatible with the fact that people have a sense of moral obligations (50). This mistake seems to result from a confusion between emic and epic concepts. Part of the emic sense of moral obligations is that you ought not escape them (at least, not so easily) when the material stakes to do so are high. However, it is a categorical mistake to criticize the epic concept of preferences just because it seems to compromise the emic sense of moral obligations. The question is empirical (whether people in fact trade-off between these motivations) rather than methodological (whether emic and epic notions of preferences must coincide-which they do not have to).

The review by Louise Barrett (2017), a professor of psychology at the University of Lethbridge, who holds a $\mathrm{PhD}$ in anthropology, is the most balanced one among the three. This is probably due to her own interdisciplinary background: she works on social cognition of human and non-human primates. While writing that Gintis's imperialistic attitude is "deeply annoying" (937), she admires the fairness with which Gintis synthesizes different camps in the debates over inclusive fitness theory (in Chapter 9), noting in general that "[t]here is room for everyone in Gintis's account" (938). She also rightly notes that Gintis's work on distributed effectivity and cognition (Chapters 3 and 5) is largely in line with the extended (or scaffolded) cognition thesis advanced by the cognitive anthropologist Edwin Hutchins (1995), the philosopher of biology Kim Sterelny (2010), and the philosopher of mind and cognitive science Andy Clark (2008). I would add to this list Wynn Stirling's (2012) game-theoretic approach to the social entanglement of preferences. The convergence of this body of work and Gintis's work on the distributed mind thesis is a recognizable trend in the behavioral sciences that needs more attention from philosophers of science.

Barrett fears, perhaps correctly, that anthropologists and sociologists who are trained in the critical tradition will not be persuaded by Gintis's call for the integrated behavioral sciences because his analysis appears to assume that "our current economic system is 
somehow inevitable" (938). Of course, this is a sloppy identification of explanation with justification. In fact, there is nothing in Gintis's analysis of economic or political systems (Chapters 4, 7 and 11) that implies the inevitability of capitalism. Chapter 4 (Power and Trust in Competitive Markets) analyses the origins of power asymmetry in the market economy, with a modest conclusion that "there is no general theory of when intervention in variable quality markets will enhance economic efficiency" (87). Moreover, Gintis does not sound particularly optimistic about the long-run success of our species:

Successful cultural changes are often maladaptive (Edgerton 1992), but so far, and in the long run, human culture has been extremely adaptive. Whether this will continue in the face of the proliferation of nuclear weapons, climate change, and reduction in biodiversity remains to be seen (2).

One might criticize this tone of detachment from the urgent emic concerns as an inevitable consequence of adopting a sociobiological perspective on human society, but this association turns out to be wrong: one of Gintis's motivations for integrating the behavioral sciences is to aid in improving socio-economic policy in the areas including "social inequality, poverty, discrimination" (275). So I hope that Barrett's impressionistic reading of Gintis as an economics imperialist and capitalist will not deepen the futile divide between the so-called 'positivist' and 'hermeneutic' camps in the social sciences.

In sum, my meta-review of these three reviews suggests that different disciplines will receive Gintis's call for unified or integrated behavioral sciences in different ways. We have observed the enthusiasm for economics imperialism, the scepticism toward rational choice models, and the pessimism over the book's ability to bridge the ideological divide in the social sciences. Although the sample size is extremely small, I suspect that these reviews simulate some of the typical reactions to Gintis's call for interdisciplinary behavioral sciences. This means that his project will face obstacles in practice, some of which are due to misunderstanding across disciplines, others more substantial. I hope that my critical comments on each reaction will alleviate the first type of obstacles and facilitate the fruitful interdisciplinary discussions that this book deserves. 


\section{REFERENCES}

Barrett, Louise. 2017. “Uniting the (Social) Sciences?” BioScience 67 (10):937-938.

Chang, Hasok. 2012. Is Water H2O? Evidence, Pluralism and Realism. Dordrecht: Springer

Clark, Andy. 2008. Supersizing the Mind: Embodiment, Action, and Cognitive Extension. Oxford: Oxford University Press.

Fuller, Steve. 2013. "Deviant Interdisciplinarity as Philosophical Practice: Prolegomena to Deep Intellectual History." Synthese 190 (11):1899-1916.

Gintis, Herbert. 2009. The Bounds of Reason: Game Theory and the Unification of the Behavioral Sciences. Princeton: Princeton University Press.

Hutchins, Edwin. 1995. Cognition in the Wild. Cambridge: MIT Press.

Longino, Helen E. 2013. Studying Human Behavior: How Scientists Investigate Aggression and Sexuality. Chicago: The University of Chicago Press.

Mitchell, Sandra D. and Michael R. Dietrich. 2006. "Integration Without Unification: An Argument for Pluralism in the Biological Sciences." The American Naturalist 168 (S6): S73-S79.

Paternotte, Cédric and Jonathan Grose. 2013. "Social Norms and Game Theory: Harmony or Discord?” The British Journal for the Philosophy of Science 64 (3):551587.

Read, Dwight. 2017. "An Economist Presents a Rational Behavior Model of Human Behavior from Sociological and Evolutionary Perspectives.” PsycCRITIQUES 62 (32): Article 6.

Sterelny, Kim. 2010. "Minds: Extended or Scaffolded?" Phenomenology and the Cognitive Sciences 9 (4):465-481.

Stirling, Wynn C. 2012. Theory of Conditional Games. Cambridge: Cambridge University Press.

Winter, Eyal. 2017. "Individuality and Entanglement, by Herbert Gintis, Princeton University Press, 2016." Journal of Behavioral and Experimental Economics 68: 140-141.

Michiru Nagatsu is Academy Researcher at the discipline of practical philosophy, University of Helsinki. His main interests include foundations of human sociality and interdisciplinary scientific practices involving economics. Nagatsu advocates more use of empirical approaches in philosophy of science, including historical, ethnographic, bibliometric and experimental methods, and practices some of these methods himself.

Contact e-mail: <michiru.nagatsu@helsinki.fi> 